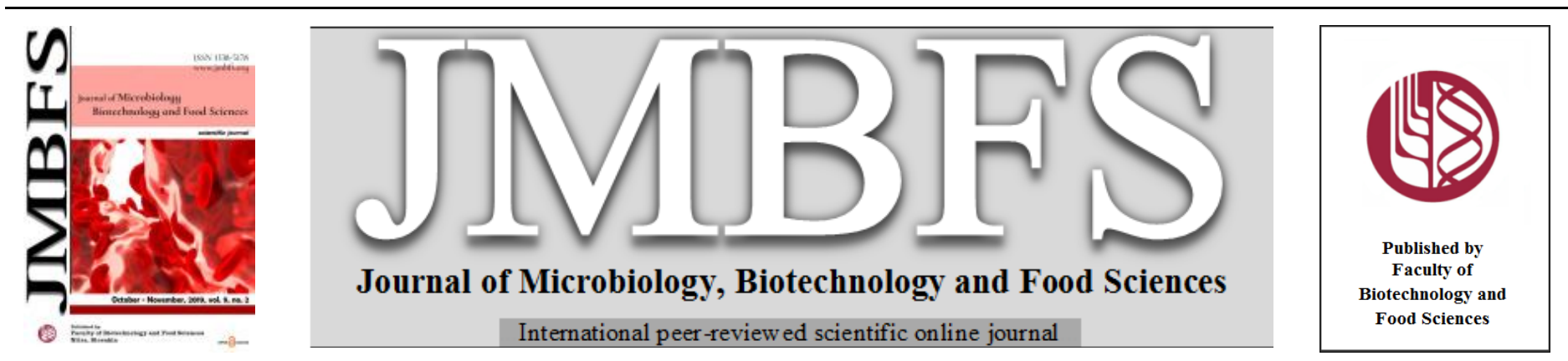

\title{
METAGENOMICS (16S AMPLICON SEQUENCING) AND DGGE ANALYSIS OF BACTERIAL DIVERSITY OF ACID MINE DRAINAGE
}

\author{
Belma Nural Yaman ${ }^{1,2}$, Mehmet Burçin Mutlü, Pınar Aytar Çelik ${ }^{2}$, Ahmet Çabuk $k^{2,4}$ \\ Address(es): \\ ${ }^{1}$ The Department of Biomedical Engineering, The Faculty of Engineering and Architecture, Eskisehir Osmangazi University, 26480 Eskisehir, Turkey. \\ ${ }^{2}$ Department of Biotechnology and Biosafety, Graduate School of Natural and Applied Science, Eskisehir Osmangazi University, 26480, Eskisehir, Turkey. \\ ${ }^{3}$ Department of Biology, Faculty of Science, Eskisehir Technical University,, Eskisehir, Turkey. \\ ${ }^{4}$ Department of Biology, Faculty of Arts and Science, Eskisehir Osmangazi University, 26480, Eskisehir, Turkey.
}

*Corresponding author: nuralbelma@gmail.com

doi: 10.15414/jmbfs.2020.9.5.932-936

ARTICLE INFO

Received 26. 2. 2019

Revised 23. 10. 2019

Accepted 11. 11. 2019

Published 1. 4. 2020

Regular article

OPEN $\partial_{\text {ACCESS }}$

\begin{abstract}
Acid mine drainages (AMDs) are characterized as low $\mathrm{pH}$ water containing metal, which is the best-known habitat for the microorganisms described as acidophiles. Most of these members do not survive above $\mathrm{pH} 4.0$; therefore they are acidophilic. Because of these metabolic properties of acidophilic microorganisms, AMD is accepted as a model system in biogeochemical studies on iron and sulfur cycles for the analysis of microbial ecology.

In this study, microbial diversity of the acid mine drainage in Çan (Çanakkale) was investigated by using culture-independent techniques including Denaturing Gradient Gel Electrophoresis (DGGE) and high-throughput sequencing.

A total of 105,593,810 and 115,689,952 bases read were performed. Following sequencing, raw data were proceeded in "Quantitative Insights Into Microbial Ecology" (QIIME 1.9.1). Acidiphilium, Acidocella and Acidosoma were genus obtained by bioinformatic analysis. The highest rate belonged to Acidiphilium for each water sample. Acidiphilium cryptum, Acidithiobacillus sp. and Acidibacter ferrireducens were determined according to DGGE analysis.
\end{abstract}

Keywords: acidophiles, diversity, metagenomics, 16S amplicon sequencing

\section{INTRODUCTION}

The best documented artificial water area associated with mining is acidic, metalrich water, commonly called as "acid mine drainage" (AMD) (Johnson and Hallberg, 2003). AMD is the best-known habitat for the acidophilic microorganisms and characterized by low pH (Chen et al., 2016) and heavy metal etc. (Johnson, 1998). The processed water from deep and surface levels of coal/metal ore mines includes the microbial load of mines near environment. This water has highly variable contaminations depending on such factors including the structures of the ore body and associated geological layers, climate and mining engineering constraints. This drainage has soluble iron and sulfide in high concentration. On the other hand, trace elements including barium, cadmium, copper, manganese, molybdenum, nickel, lead, selenium and zinc in acid mine drainage are in a lower concentration than iron due to three main reasons (Johnson, 2003). First of all, heavy metals and metalloids have been organized as sulfide minerals and accelerate microbial oxidative dissolution. Secondly, solutions with rich acidic ferric iron occur after pyrite dissolves aggressively. Finally, numerous metals are more soluble in acidic waters (Johnson, 2003).

Microbiota in acidic and metal rich environments has substantial variety. Many of these members are acidophilic and do not survive above $\mathrm{pH} 4.0$ (Johnson, 1998). Therefore, acidophilic microorganisms isolated from acidic environments $(\mathrm{pH}<3)$ have both metabolic and phylogenetic diversities (Johnson, 2003; Johnson and Hallberg, 2003; Johnson and Hallberg, 2005; Oren, 2010). Acidophilic microorganisms are classified as anaerobic, aerobic and facultative according to use of oxygen and are classified as phototrophic, chemotrophic, heterotrophic according to nutrition synthesis (Oren, 2010; Chen et al., 2016) Microbial species growing in acidic environments can use iron, sulfur, nitrogen, carbon and oxygen in their metabolisms. Sub-cycling of these elements was described in some starting studies. Different models were shown for only iron and sulfur cycling in remarkable examples. These studies were carried out by biomolecular and culture-dependent methods and more recently omics approaches (Méndez-García et al., 2015).

Acidophiles have evolved by developing adaptations to the extreme conditions and these adaptations have effectively accelerated acid production process (Chen et al., 2016). For this reason, they have a vital role in the conservation of energy and material flow in the ecosystem/ microenvironment. AMD environments are ideal targets for biogeochemical studies on iron and sulfur cycles as model systems for quantitative analysis of microbial ecology and community function (Navarro et al., 2013; Johnson, 2014; Chen et al., 2016;Gumulya et al., 2018).

Metagenomics was firstly used by Handelsman and co-workers (Handelsman et al., 1998) for analysis of function and sequencing of microbial genomics extracted from environmental samples. The shotgun metagenomics have the full recruitment capacity of most of the genomes present in an environmental sample. This creates the biodiversity profile associated with a functional analysis of known and unknown organism species. With shotgun metagenomics, answers were given to the question of who is present in the environmental community, what they are doing functionally and how they interact in ecological location. Nowadays, the metagenomics approach of a marker gene in which the related genetic polymerase chain reaction is used. The marker gene metagenomics in which the respective genes are located is used for the fingerprint or taxonomic distribution of the conserved 16S rRNA gene region. This approach has received considerable attention recently in microbial diversity studies (Oulas et al., 2015). Jones and coworkers (2012) have investigated the community, physiology and biogeochemistry of biofilm via metagenomics, rRNA methods and lipid geochemistry. They have found Acidithiobacillus thiooxidans (>70) as dominant species, and Thermoplasmatales represented with small population in low level (Jones et al., 2012).

Chen and colleagues (2015) have studied metagenomic and metatranscriptomic analysis of microbial diversity in AMD. They found Acidithiobacillus, Leptospirillum and Acidiphilium with high transcriptional activities as a result of taxonomic analysis. They have investigated microorganisms which are adapted to the AMD environment by regulating the expressed genes contained in multifunctional activities, especially low $\mathrm{pH}$ and other activities in organismwide comparative analyses (Chen et al., 2015).

In another study, Liljeqvist et al., (2015) have studied a diversity of microorganisms equipped for growth at low temperatures and acidic $\mathrm{pH}$ in AMD in Kristineberg, Sweden. They have done metagenomic analysis of the biofilm and planktonic fractions and found that microorganism to be similar to the psychrotolerant acidophile, Acidithiobacillus ferrivorans. Metadata showed Acidithiobacillus species, an Acidobacteria-like species, and a Gallionellaceaelike species. Furthermore, they have predicted genes which encode functions 
related to $\mathrm{pH}$ homeostasis and metal resistance related to growth in acid mine water (Liljeqvist et al., 2015).

The aim of this study was to show the microbial diversity of AMD in Çan, Turkey with culture-independent methods including DGGE and metagenomics (16S amplicon sequencing). In addition to the fact that there are few studies with a metagenomics approach for determining acidophile microbial diversity in the world, this study will constitute as the first metagenomics data to literature concerning acidophilic microorganism diversity in Turkey. We investigated the population structure in water samples from acid mine drainage and found that microorganism with heterotrophic character according to metadata. Similar results have been exhibited via DGGE analysis.

\section{MATERIALS AND METHODS}

\section{Sampling area}

Water samples were collected from the surface of the AMD in Çan, Turkey (March, 2017). The sampling area was located at $39^{\circ} 58^{\prime} 7^{\prime \prime} \mathrm{N}, 26^{\circ} 51^{\prime} 55^{\prime \prime} \mathrm{E}$ (Figure 1). Two samplings of this area were performed and the $\mathrm{pH}$ values of samples were measured

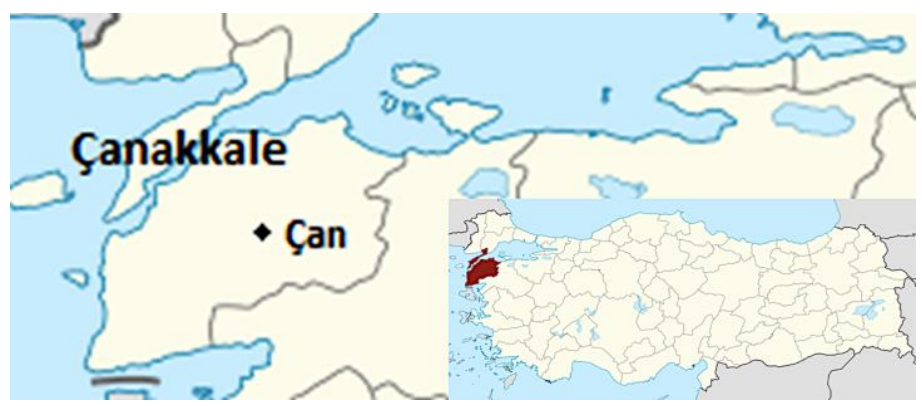

Figure 1 Sampling area on Turkey map

\section{Chemical analysis of samples}

Water samples were sent to commercial measurement services (Acme Analytical Lab. Ser. Co. Ltd., Ankara, Turkey) to analyze the metal and semi-metal contents of samples. ICP-MS (PerkinElmer, ELAN 9000) was used to determine concentrations of elements.

\section{Total DNA extraction and metagenomics analysis}

GTTP membrane filters $(0,22 \mu \mathrm{m}$ pore size, Merck Millipore, Germany) were used to collect the microorganisms. Two water samples were filtered by vacuum pump. These filtrates were broken up to into small pieces and total DNA was extracted using UltraClean ${ }^{\circledR}$ Microbial DNA Isolation Kit (MoBio Laboratories, USA) according to the manufacturer's instructions. The DNA was analysed by $1 \%$ agarose gel electrophoresis and imaged by Gel DocTM XR+ System with Image LabTM Software (BIO-RAD). The DNA concentrations were measured by NanoDrop ${ }^{\text {TM }}$ 2000/c Spectrophotometers (Thermo Scientific, USA).

DNA from these water samples were also sent to a commercial sequencing service (BM Software Consultancy and Lab. System Co. Ltd. Ankara, Turkey) for metagenomic analysis. The analysis was $16 \mathrm{~S}$ Ribosomal RNA Gene Amplicons by the Illumina MiSeq System. The target in NGS analysis was V3 V4 region amplified with the 341F (CCTACGGGNGGCWGCAG) and 805R (GACTACHVGGGTATCTAATCC) primer pair for prokaryotes. $2.5 \mu \mathrm{L}$ of microbial environmental DNA was used as a template for amplification of V3-V4 region. The reaction was performed in a total volume of $25 \mu \mathrm{L}$ including $12.5 \mu \mathrm{L}$ of 2x KAPA HiFi Hot Start ReadyMix, $5 \mu \mathrm{L}$ of each Amplicon PCR Primers (1 $\mu \mathrm{M})$. The reaction conditions comprise of the initial denaturation step at $95{ }^{\circ} \mathrm{C}$ for 3 minutes, 25 cycles at $95{ }^{\circ} \mathrm{C}$ for 30 seconds, $55^{\circ} \mathrm{C}$ for 30 seconds, and $72^{\circ} \mathrm{C}$ for 30 minutes then final extension step at $72^{\circ} \mathrm{C}$ for 5 minutes. AMPure XP beads were used to purify the free primers and primer dimer species in the amplicon product. Index PCR attaches the Illumina Sequencing adapter via Nextera XT Index Kit. N719 (GCGTAGTA) - N515 (TTCTAGCT) (index sequence for Ç1) and N719 (GCGTAGTA) - N516 (CCTAGAGT) (index sequence for Ç2) index primers were used in amplification with 8 cycles. AMPure XP beads were again used to clean up the final library. Validation process was performed on Bioanalyzer DNA 1000 chip. Sequencing was practiced by the Illumina Miseq platform (Illumina Miseq, 16S Metagenomic Sequencing Library Preparation Part \# 15044223 Rev. B).

\section{Bioinformatics analysis of metagenomics raw data}

Raw data were processed with QIIME 1.9.1 (http://qiime.org/) by entering the specific commands in Linux. Mapping files including sample names, barcode sequence, linker primers sequences, description and any information about sampling area were prepared. Libraries were processed together using QIIME version 1.9.1 (Caporaso et al., 2010a). Poor-quality sequences were discarded based on Phred score, primer mismatches, divergence from expected amplicon length (298 base pairs) using the default settings in QIIME (split_libraries_fastq.py). Sequences were clustered into de novo operational taxonomic units (OTUs) at 97\% similarity using QIIME's pick_de_novo_otus.py command. Singleton OTUs (defined as OTUs represented by only a single representative sequence across all samples) were discarded. Representative sequences from each OTU were aligned using PyNAST (Caporaso et al., 2010b) and classified according to the Greengenes taxonomy (version gg_13_8; McDonald et al., 2012). After the quality filtering process, 61,372 valid sequences remained and were used in subsequent analysis. Then the readpair merging approximately $75 \%$ of the reads were remained.

\section{Denaturating gradient gel electrophoresis (DGGE) analysis}

DGGE PCR products were amplified using total DNA as a template in reaction mix. 341F-GC and 907R pair of primers were used for Bacteria domain respectively as forward and reverse primer to amplify products in 2xMaster Mix (Ampliqon, Denmark). Touchdown PCR was used in DGGE analysis. PCR was implemented in $5 \mathrm{~min}$ at $94{ }^{\circ} \mathrm{C}, 1 \mathrm{~min}$ at $65{ }^{\circ} \mathrm{C}, 3 \mathrm{~min}$ at $72{ }^{\circ} \mathrm{C}$ for first cycle; next 9 cycles were performed with decreasing $1{ }^{\circ} \mathrm{C}$ in annealing step per every cycle. The next 20 cycles was implemented in $1 \mathrm{~min}$ at $94{ }^{\circ} \mathrm{C}, 1 \mathrm{~min}$ at $55^{\circ} \mathrm{C}, 3$ min at $72{ }^{\circ} \mathrm{C}$. The last cycle was implemented in $1 \mathrm{~min}$ at $94{ }^{\circ} \mathrm{C}, 1 \mathrm{~min}$ at $55^{\circ} \mathrm{C}$, $10 \mathrm{~min}$ at $72{ }^{\circ} \mathrm{C}$. DGGE PCR products were run into $1 \%$ Agarose Gel Electrophoresis and imaged by Gel DocTM XR+ System with Image LabTM Software (BIO-RAD). 16S PCR products from agarose gel were cleaned up using GeneJETTM Gel Extraction Kit (Fermentas).

DGGE analysis was performed with D-Code System (BioRad) according to modified protocols describing by Muyzer and coworkers (Muyzer et al., 1993). The samples were loaded into DGGE gels containing polyacrylamide with a urea-form amide gradient being from $40 \%$ to $60 \%$. The gel was run at $90 \mathrm{~V}$ for $18 \mathrm{~h}$.

Each of bands were cut from the gel and put in the new tubes. DGGE lysis buffer was added on the bands in the tubes which were incubated horizontally at $37^{\circ} \mathrm{C}$. Once incubation, DGGE Re-PCR were performed using liquid section as a template. The PCR products were loaded in gel and run at $100 \mathrm{mV}$ in 70 minutes. The products given as positive bands were sent to commercial sequencing service (BM Software Consultancy and Lab. System Co. Ltd., Ankara, Turkey) for DNA sequence analysis. Chromatograms were analyzed via 4Peaks and the sequences of each band were aligned via BLAST $\mathrm{n}$ Nucleotide (nr/nt databank). The accession numbers were provided by submitted the information of uncultured environmental DNA sequences to Submission Portal (https://submit.ncbi.nlm.nih.gov/subs/genbank/).

\section{RESULTS}

\section{Metal contents of sampling area}

$\mathrm{pH}$ values were measured in water samples belonging to $\mathrm{C} 1$ and $\mathrm{C} 2$ as 3.0 and 2.9 , respectively. Concentrations of metal contents in these samples were mentioned in Table 1. Concentrations of the metals mentioned in the table are given as ppb or ppm. When the obtained data were analyzed, it can be seen that there were dominantly chemicals such as aluminum (Al), boron (B), calcium $(\mathrm{Ca})$, cobalt $(\mathrm{Co})$, iron $(\mathrm{Fe})$, sulfur $(\mathrm{S})$, strontium $(\mathrm{Sr})$, potassium $(\mathrm{K})$, magnesium $(\mathrm{Mg})$, zinc $(\mathrm{Zn})$, manganese $(\mathrm{Mn})$ and sodium $(\mathrm{Na})$ in water samples. These chemicals and their concentrations were indicated as bold in previously mentioned table.

Table 1 Metal analysis of water samples from acid mine drainage

\begin{tabular}{lll} 
METAL & Ç1 & Ç2 \\
AL (PPB) & 20423 & 15211 \\
B (PPB) & 966 & 989 \\
CA (PPM) & 326.2 & 324.6 \\
CO (PPB) & 549 & 532 \\
FE (PPB) & 10965 & $<10000$ \\
K (PPM) & 11 & 12 \\
MG (PPM) & 108 & 105 \\
MN (PPB) & 28618 & 28296 \\
NA (PPM) & 219 & 219 \\
S (PPM) & 565 & 538 \\
SR (PPB) & 2273 & 2275 \\
ZN (PPB) & 1040 & 843 \\
\hline
\end{tabular}

\section{Total DNA extraction}

Concentrations of DNA from C1 and C2 were respectively found as $25.9 \mathrm{ng} / \mu \mathrm{L}$ and $26 \mathrm{ng} / \mu \mathrm{L}$. The absorbance ratio between $260 \mathrm{~nm}$ and $280 \mathrm{~nm}$ was shown to measure protein contamination. This value must be greater than or equal to 1.8 The A260/280 ratios of DNAs from Ç1 and Ç2 were 1.99 and 2.02, respectively. 


\section{Processing of Raw Data}

During the analysis, total $104,865,386$ read bases (bp) of total 349,928 reads were carried out for the Ç1 sample. In the same procedure, total 114,909,694 read bases (bp) of total 383,426 reads were performed for the Ç2 sample (Table 2). After analyses of two environmental water samples, there was no record in domain Archaea but domain Bacteria had $90.5 \%$ of total reading. Approximately
$9.5 \%$ of remaining of the total reading was unassigned. Results could be given separately at the levels of phylum, class, order, family, genus and species. The information expressed in a column graphs could be considered meaningful. Proteobacteria $(38.60 \%)$, Actinobacteria $(16.80 \%)$ and Acidobacteria $(8 \%)$ were the phyla of Bacteria have the most members than other phyla for the Ç1 water sample (Figure 2).

Table 2 Raw data Stats (Sample ID : Sample name; Total read bases : Total number of bases sequenced; Total reads:Total number of reads; $\mathrm{GC}(\%)$ : GC content; AT(\%) : AT content; Q20(\%) : Ratio of reads that have phred quality score of over 20; $\mathrm{Q} 30(\%)$ : Ratio of reads that have phrased quality score of over 30)

\begin{tabular}{lcccccc} 
SAMPLE ID & TOTAL READ BASES & TOTAL & GC $(\%)$ & AT $(\%)$ & Q20(\%) & Q30(\%) \\
Ç1 & $(\mathrm{BP})$ & READS & & & 83.569 & 74.753 \\
Ç2 & $105,593,810$ & 350,810 & 55.424 & 44.58 & 74.787 \\
\hline
\end{tabular}

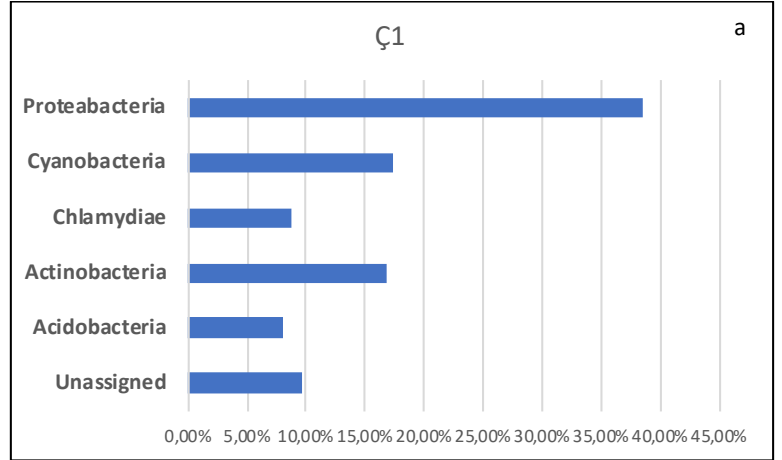

Figure 2 Graphical view at phylum level of $\mathrm{m}$

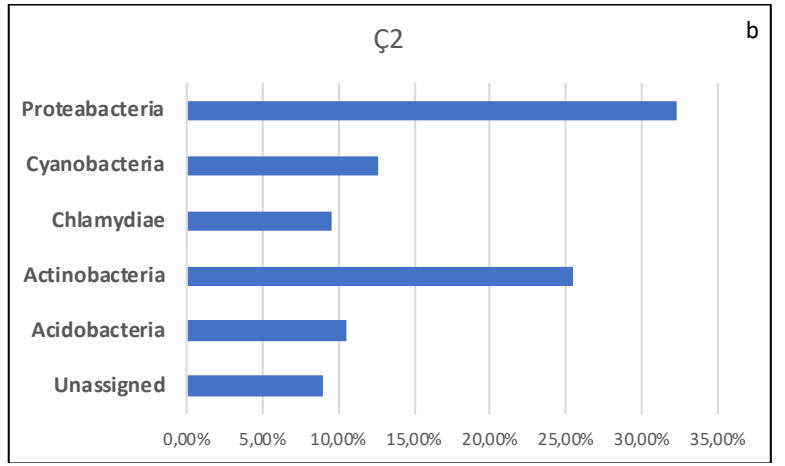

The results for the $\mathrm{C} 2$ water samples were similar as results of $\mathrm{C} 1$. Proteobacteria $(32.30 \%)$, Actinobacteria $(25.50 \%)$ and Acidobacteria $(10.50 \%)$ were phyla including the most members for $\mathrm{C} 2$ water sample. Proteobacteria in metadata of water samples has three classes at the taxonomic level named as Alphaproteobacteria, Betaproteobacteria and Gammaproteobacteria. Actinobacteria and Acidobacteria have a taxonomic class being Acidimicrobiia and Acidobacteriia, respectively. Acidobacteriales, Acidomicrobiales, Ellin329, Rhodospirillales, Methylophilales, Legionellales and Xanthomonaales were found at the level of taxonomic order. Acidobacteriaceae, Acidimicrobiaceae and Acetobacteraceae were encountered most strikingly at the level of taxonomic family. Acidiphilium was the only identified genus taxon in all results with highest percentage. Acidosoma and Acidocella were found at a considerable
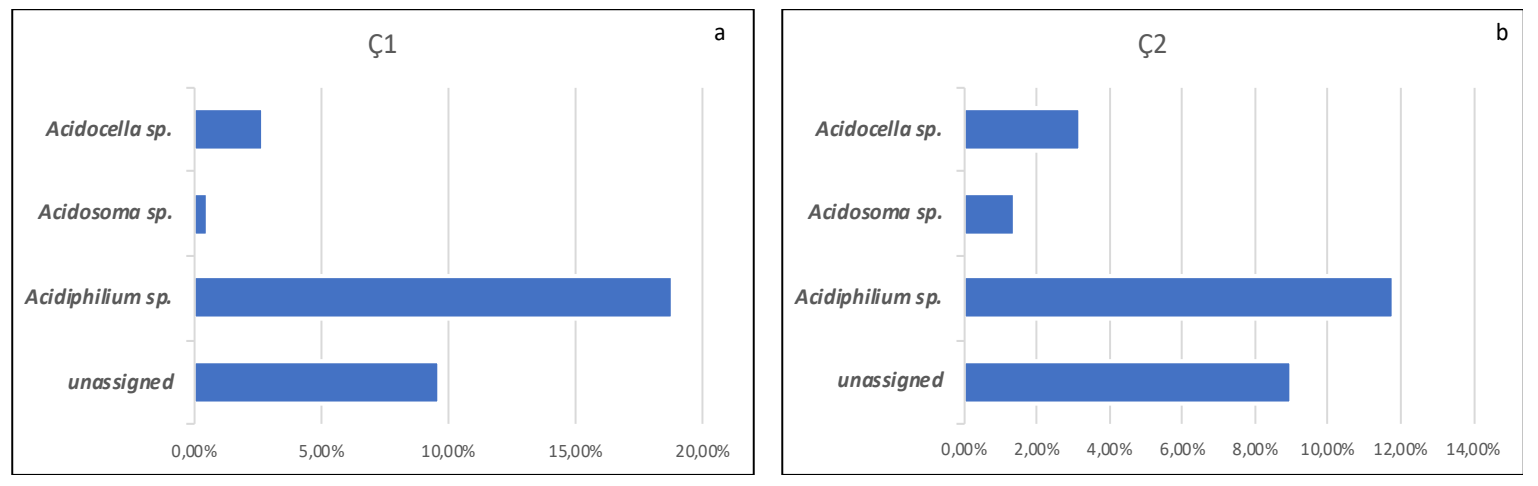

amount following the genus Acidiphilium (Figure 3). No detailed description at the species level has been obtained. Proteobacteria in Ç1 AMD water sample has members of Alphaproteobacteria (30.40\%), Betaproteobacteria (4.60\%) and Gammaproteobacteria (3.70\%) classes and Ç2 AMD water sample has member of Alphaproteobacteria $(25.40 \%)$, Betaproteobacteria $(2.60 \%)$ and Gammaproteobacteria $(4.40 \%)$ classes. $15.10 \%$ of total reading is Acidiphilium and $18.80 \%$ of this genus is in microorganisms of Ç1 and $11.80 \%$ of this genus is in microorganisms of Ç2.

Figure 3 Graphical view at genus level of metagenomics data. a) genera of Ç1 b) genera of Ç2

\section{DGGE analysis}

The Figure 4 shows four DGGE bands having of each environmental water samples. The bands were indicated with arrow and numbers. Arrows 1 and 2 indicate the Ç1 sample's diversity and arrows 3 and 4 indicate the Ç2 sample's diversity. According to BLAST alignment, Ç1-1 and Ç1-2 were described as an uncultured bacterium and uncultured Acidiphilium cryptum in Ç1 sample DGGE profile. Furthermore, Ç2-1 and Ç2-2 were described respectively uncultured bacterium and uncultured Acidithiobacillus sp in Ç2 sample DGGE profile. 


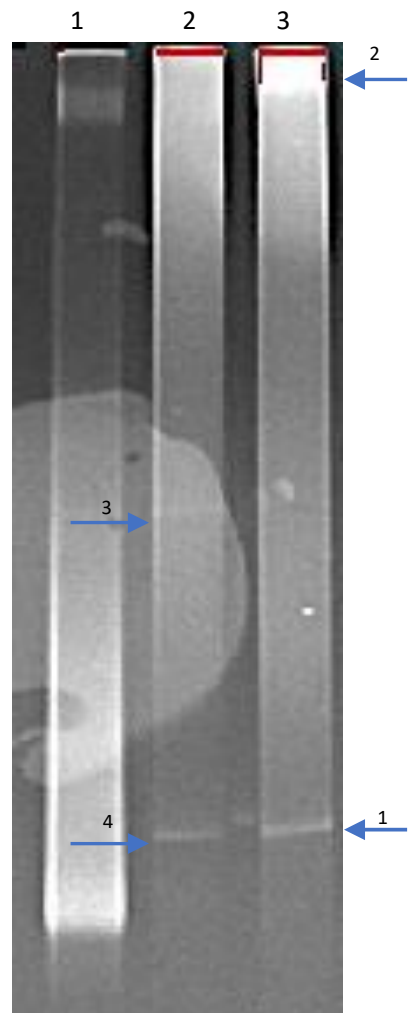

Figure 4 DGGE gel of environmental samples, 1: acidophilic microorganism BY16, 2:Ç2, 3:Ç1. Arrow 1 and 2 belong to sample Ç1; arrow 3 and 4 belong to sample Ç2.

The found results and accession numbers were given in Table 3. The microbial diversity was showed with phylogenetic tree (Neighbor Joining Method) constructed by using MEGA 7.0 and a non-relative species (Methylobacter bovis L20839) to see true distance of species was used in this tree (Figure 5). The percentage matrixes of these sequences constructed by Muscle Software are given in Table 4. Acidibacter ferrireducens strain MCF85 from C1 and C2 showed approximately $97.3 \%$ percentage identity. Acidiphilium cryptum and Acidithiobacillus sp. had $74.20 \%$ percentage identity.

Table 3 DGGE bands and accession numbers

\begin{tabular}{llll}
\hline DGGE & $\begin{array}{l}\text { Accession } \\
\text { Nands }\end{array}$ & BLAST/n & $\begin{array}{l}\text { Analyzed Base } \\
\text { Number }\end{array}$ \\
\hline Ç1-1 & MH729781 & $\begin{array}{l}\text { Uncultered Acidibacter } \\
\text { sp. }\end{array}$ & $591 \mathrm{bp}$ \\
Ç1-2 & MH735136 & $\begin{array}{l}\text { Uncultured Acidiphilium } \\
\text { cryptum }\end{array}$ & $640 \mathrm{bp}$ \\
Ç2-1 & MH735137 & $\begin{array}{l}\text { Uncultered Acidibacter } \\
\text { sp. }\end{array}$ & $593 \mathrm{bp}$ \\
Ç2-2 & MH735145 & $\begin{array}{l}\text { Uncultured } \\
\text { Acidithiobacillus sp. }\end{array}$ & $592 \mathrm{bp}$ \\
\hline
\end{tabular}

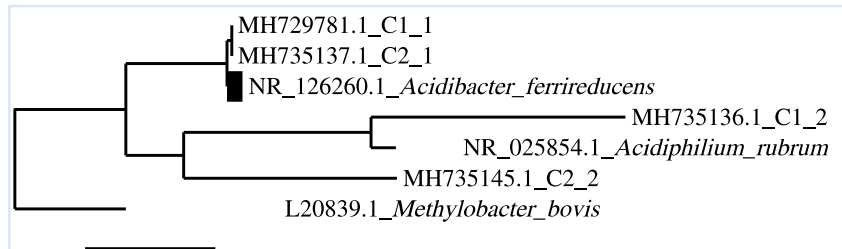

0.1

Figure 5 The phylogenetic tree of DGGE bands

Table 4 Percent Identity of DGGE bands sequence

\begin{tabular}{|c|c|c|c|c|}
\hline & $\begin{array}{l}\text { Ç1-2 } \\
(M H 735136)\end{array}$ & $\begin{array}{l}C \zeta 2-2 \\
(M H 735145)\end{array}$ & $\begin{array}{l}\text { Ç1-1 } \\
(M H 729781)\end{array}$ & $\begin{array}{l}C ̧ 2-1 \\
(M H 735137)\end{array}$ \\
\hline $\begin{array}{l}\text { Ç1-2 } \\
\text { (MH735136) }\end{array}$ & 100.00 & 74.20 & 75.22 & 75.27 \\
\hline $\begin{array}{l}C \zeta 2-2 \\
(M H 735145)\end{array}$ & 74.20 & 100.00 & 80.34 & 80.03 \\
\hline $\begin{array}{l}\text { Ç1-1 } \\
(\text { MH729781) }\end{array}$ & 75.22 & 80.34 & 100.00 & 99.15 \\
\hline $\begin{array}{l}C \zeta 2-1 \\
(\text { MH735137) }\end{array}$ & 75.27 & 80.03 & 99.15 & 100.00 \\
\hline
\end{tabular}

\section{DISCUSSION}

Metagenomic studies have been increasing day by day. This approach enables to evaluate better microbial diversity of extreme environments. In this study, Acidobacteria, Proteobacteria, Actinobacteria were detected as dominant phyla according to metagenomic analysis. Other studies utilizing $16 \mathrm{~S}$ amplicon sequencing of diversity of acidophilic microorganisms have also been reported. Miller and colleagues reported results concerning 16S amplicon sequencing (Illumina Miseq platform; V3-V4 region amplification) of samples in AMD from Colorado. They have revealed Proteobacteria, Actinobacteria, Chlorofexi, and Firmicutes phyla with higher relative abundance from AMD samples (Miller et al., 2018). On the other hand, Aguinaga and colleagues have published an article about $16 \mathrm{~S}$ gene amplicon sequencing of sediments from AMD. In this study, Protebacteria has been found as dominant phylum in this area. Bacterioideles, Acidobacteria, Cyanobacteria and Actinobacteria respectively higher relative abundance from AMD area (Aguinaga et al., 2018).

AMD waters were characterized as potentially toxic metals including trace and semi-metal, therefore a lot of metal ions in these water samples are expected. It has been known that mining waters are characterized by these metal ions. There were different metals in this study, but iron, phosphorus, lead and manganese were the highest value in analysis.

DGGE analysis showed similar results to metagenomic analysis. Acidibacter $\mathrm{sp}$ Acidiphilium cryptum and Acidithiobacillus sp. were the names of bands defined in profile. Another different result is the presence of Acidithiobacillus sp. not being seen in the metagenomic analysis. It is known that Acidithiobacillus sp. produces energy by oxidizing the $\mathrm{Fe}$ (II) to reduction of $\mathrm{O}_{2}$ (White et al., 2016). The Fe ion content of C 2 sample has rather high value in other metal contents. In other studies, data related DGGE analysis has been reported by researches. Gonzalez-Toril and colleagues analyzed the microbial community from AMD in Tinto River by using molecular ecology techniques including DGGE approach 16S rDNA DGGE-PCR amplification was performed with $341 \mathrm{~F}$ and 907R primer pair for Bacteria and 344F and 915R primer pair for Archaea. They found members of different phylogenetic groups including $\gamma$-Proteobacteria, $\alpha$ Proteobacteria, Nitrospira, Actinobacteria and Thermoplasmata in the result of analysis. The population structure contained Acidithiobacillus sp. Acidithiobacillus ferrooxidans, Leptospirillum ferrooxidans, Acidiphilium sp., Ferrimicrobium acidiphilum, Ferroplasma acidiphilum (Gonzalez-Toril et al., 2003). Hamamura and colleagues have studied bacterial communities related to hydrocarbon seep in soils in other study. They have performed experiments by molecular techniques including clone library and DGGE profile. They performed 16S rDNA DGGE PCR amplification with $1070 \mathrm{~F}$ and $1392 \mathrm{R}$ primer pairs for Bacteria. According to DGGE analysis they described as Acidocella sp, Acidiphilium acidophilum, Acidobacteriaceae isolate (Hamamura et al., 2005). According to metagenomics results, microbial diversities of these water samples have heterotrophic character because described genera with the most percentage are Acidiphilium and Acidocella. Among this genera, Acidiphilium shows heterotrophic and acidophilic character from $\alpha$-Proteobacteria (Johnson 2007). Acidocella is heterotroph genus like Acidiphilium but this genus could tolerate less extreme acidity and heavy metal concentration than Acidiphilium (Johnson 2007). With reference to metagenomic data in this study, it was found that Acidiphilium had more members than Acidocella. Aytar et al. took samples from same location during March 2012. They studied using culture-dependent and culture-independent methods. They have also isolated heterotroph acidophilic microorganisms from Çan (Aytar et al., 2015). Aytar and colleagues have reported the presence of Ferroplasma-like prokaryotes according to the results of T-RFLP and qPCR analyses. qPCR generated semiquantitative data for genera of some of the iron-oxidizing acidophiles isolated and/or detected, suggesting the order of abundance was and Ferroplasma $>$ Leptospirillum $>$ Acidithiobacillus in Çan AMD. They described Acidiphilium spp.; Acidithiobacillus and Leptospirillum spp. according to terminal restriction fragment analysis. In the same study, strains of Leptospirillum ferriphilum, Acidicapsa ligni, and Acidiphilium rubrum were isolated from Çan AMD using culture-dependent technique (Aytar et al., 2015). Previous results and given results in this paper are compatible. There is no finding information about Acidithiobacillus and Leptospirillum spp in this study. It may be due to change of $\mathrm{pH}$, because $\mathrm{pH}$ value of this area was reported as 2.8 in March 2012. Besides, increase of organic matter may occur. It is thought that difference of metal contents may cause a decrease in microbiological diversity. In March 2012, it was reported that aluminum, chromium, and copper were greater in Çan AMD (Aytar et al., 2015), but in this study, iron, phosphorus, lead and manganese were found greater than other metals or semi-metals.

Acidophilic microorganisms can survive in high heavy metal concentrations through active metal resistance system in their adaptation mechanisms. It is thought that undefined resistance mechanisms will contribute to current acidophile metal resistance mechanisms (Dopson et al., 2014).

The resistance against to some heavy metals has been reported in Acidiphilium species. The arsB gene was found by hybridization technique in some acidophiles containing Acidiphilium and Acidocella. Acidiphilium symbioticum has three plasmids contributing to resistance against metal ions of $\mathrm{Zn}$ (II) and $\mathrm{Cd}$ (II). Moreover among acidophiles, Acidiphilium multivorum, Acidocella aminolytica 
and Acidocella strain GS19 have resistance to $\mathrm{Ni}$ (II) ion (Bhowal and Chakraborty 2015). The metagenomic data also reveals Acidiphilium and Acidocella as dominant genera in samples. As (arsenic), Zn (zinc), Cd (cadmium) and $\mathrm{Ni}$ (nickel) were found as considerably higher concentrations than reference values in this study.

Another study reported that the copper resistance caused the morphological variety in cells of Acidiphilium symbioticum. Acidophiles have tolerated high copper concentrations $(>100 \mathrm{mM})$. Furthermore, acidophiles living in mining environment could better survive and grow in presence of copper than acidophiles in other environments (Dopson and Holmes, 2014).

\section{CONCLUSION}

Microbial diversity of AMD in Çan was studied by a metagenomic approach contributing as a metadata to literature with this first study from Turkey. This group of extremophiles has vital importance in laboratory and industria applications due to of surviving in low $\mathrm{pH}$ and having active metabolism optimum in low $\mathrm{pH}$

Acknowledgements: This study was supported by Eskișehir Osmangazi University Scientific Research Project Committee (Project No: 2017/19D12). Belma NURAL YAMAN is supported by TUBITAK-BIDEB 2228-B National Scholarship Program for PhD Students.

Conflict of Interest Statement: All authors declare that there are no financial commercial conflicts of interest.

\section{REFERENCES}

Aguinaga, O. E., McMahon, A., White, K. N., Dean, A. P., Pittman, J. K. (2018) Microbial community shifts in response

to acid mine drainage pollution within a natural wetland ecosystem Frontiers in Microbiology 9,1445. https://doi.org/10.3389/fmicb.2018.01445

Aytar, P., Kay, C. M., Mutlu, M. B., Çabuk, A., Johnson, D. B. (2015). Diversity of acidophilic prokaryotes at two acid

mine drainage sites in Turkey. Environmental Science and Pollution Research 22 (8), 5995-6003. https://doi.org/ https://doi.org/10.1007/s11356-014-3789-4

Bhowal, S. S., Chakraborty, R. (2015). Microbial Diversity Of Acidophilic Heterotrophic Bacteria: an overview. In: Jha P (ed) Biodiversity, Conservation and Sustainable Development, vol Vol.1: Issues and Approaches. New Academic Publishers, New Delhi, pp. 157-174.

Caporaso, J. G., Kuczynski, J., Stombaugh, J., Bittinger, K., Bushman, F. D., Costello, E. K., et al. (2010a). QIIME allows analysis of high-throughput community sequencing data. Nat. Methods 7, 335-336. doi: $10.1038 /$ nmeth.f.303 Caporaso, J. G., Bittinger, K., Bushman, F. D., DeSantis, T. Z., Andersen, G. L. and Knight, R. (2010b). PyNAST:a flexible tool for aligning sequences to a template alignment. Bioinformatics 26, 266-267. doi 10.1093/bioinformatics/btp636

Chen, L.X., Hu, M., Huang, L. n., Hua, Z. s., Kuang, J. 1., Li, S. j., Shu, W. s. (2015). Comparative metagenomic and metatranscriptomic analyses of microbial communities in acid mine drainage The ISME journal 9:1579-1592. https://doi.org/10.1038/ismej.2014.245

Chen, L. x., Huang, L. n., Méndez-García, C., Kuang, J. 1., Hua Z, s., Liu, J., Shu, W. s. (2016). Microbial communities, processes and functions in acid mine drainage ecosystems Current opinion in biotechnology 38:150-158 https://doi.org/10.1016/j.copbio.2016.01.013

Dopson, M., Holmes, D. S. (2014). Metal resistance in acidophilic microorganisms and its significance for biotechnologies. Applied microbiology and biotechnology 98:8133-8144. https://doi.org/10.1007/s00253-014-5982-2

Dopson, M., Ossandon, F. J., Lövgren, L., Holmes, D. S. (2014). Metal resistance or tolerance? Acidophiles confront high metal loads via both abiotic and biotic $\begin{array}{lll}\text { mechanisms. Frontiers in microbiology, } & \text { 5,157 }\end{array}$ https://doi.org/10.3389/fmicb.2014.00157

Gonzalez-Toril, E., Llobet-Brossa, E., Casamayor, E., Amann, R., Amils, R. (2003). Microbial ecology of an extreme acidic environment, the Tinto River.

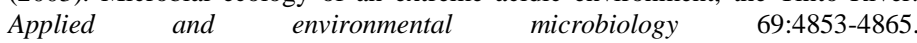
https://doi.org/10.1128/AEM.69.8.4853-4865.2003

Gumulya, Y., Boxall, N. J., Khaleque, H. N., Santala, V., Carlson, R. P., Kaksonen, A. H. (2018). In a quest for engineering acidophiles for biomining applications: challenges and opportunities. Genes, 9(2), 116 https://doi.org/10.3390/genes9020116

Hamamura, N., Olson, S. H., Ward, D. M., Inskeep, W. P. (2005). Diversity and functional analysis of bacterial communities associated with natural hydrocarbon seeps in acidic soils at Rainbow Springs, Yellowstone National Park. Applied and environmental microbiology, 71, 5943-5950. https://doi.org/10.1128/AEM.71.10.5943-5950.2005

Handelsman, J., Rondon, M. R., Brady, S. F., Clardy, J., Goodman, R. M. (1998) Molecular biological access to the chemistry of unknown soil microbes: a new frontier for natural products. Chemistry \& Biology, 5, R245R249.https://doi.org/10.1016/S1074-5521(98)90108-9
Johnson, D. B. (1998). Biodiversity and ecology of acidophilic microorganisms. FEMS microbiology ecology, 27, 307-317 https://doi.org/10.1111/j.15746941.1998.tb00547.x

Johnson, D. B. (2003). Chemical and microbiological characteristics of mineral spoils and drainage waters at abandoned coal and metal mines. Water, Air and Soil Pollution: Focus, 3, 47-66. https://doi.org/10.1023/A:1022107520836.

Johnson, D. B., Hallberg, K. B. (2003). The microbiology of acidic mine waters. Research in microbiology, 154, 466-473. https://doi.org/10.1016/S0923 2508(03)00114-1

Johnson, D. B., Hallberg, K. B. (2005). Acid mine drainage remediation options: a review. Science of the total environment, 338, 3-14 https://doi.org/10.1016/j.scitotenv.2004.09.002

Johnson, D. B. (2007). Physiology and ecology of acidophilic microorganisms. In: Physiology and biochemistry of extremophiles. American Society of Microbiology, pp 257-270. https://doi.org/10.1128/9781555815813.ch20.

Johnson, D. B. (2014). Biomining-biotechnologies for extracting and recovering metals from ores and waste materials. Current opinion in biotechnology, 30, 24-31. https://doi.org/10.1016/j.copbio.2014.04.008

Jones, D. S., Albrecht, H. L., Dawson, K. S., Schaperdoth, I., Freeman, K. H., Pi, Y., Pearson, A., Macalady, J. L. (2012). Community genomic analysis of an extremely acidophilic sulfur-oxidizing biofilm. The ISME journal, 6, 158-170. https://doi.org/10.1038/ismej.2011.75

Liljeqvist, M., Ossandon, F. J., González, C., Rajan, S., Stell, A., Valdes, J., Holmes, D. S., Dopson, M. (2015). Metagenomic analysis reveals adaptations to a cold-adapted lifestyle in a low-temperature acid mine drainage stream. FEMS Microbiology Ecology, 91(4), fiv011. https://doi.org/10.1093/femsec/fiv011

McDonald, D., Price, M. N., Goodrich, J., Nawrocki, E. P., DeSantis, T. Z., Probst, A., et al. (2012). An improved Greengenes taxonomy with explicit ranks for ecological and evolutionary analyses of bacteria and archaea. ISME J. 6, 610 618. doi: 10.1038/ismej.2011.139

Méndez-García, C., Peláez, A. I., Mesa, V., Sánchez, J., Golyshina, O. V., Ferrer, M. (2015). Microbial diversity and metabolic networks in acid mine drainage $\begin{array}{llll}\text { habitats. Frontiers in microbiology, } & 6(475), & \text { 1-17. }\end{array}$ https://doi.org/10.3389/fmicb.2015.00475

Miller, R. K., Kirkham, R. M., Kleinschmit, A. J. (2018). Bioinformatics Analysis of Microbial Abundance and Diversity in Acid Mine Drainage from the Solomon Mine Near Creede, Colorado. Fine Focus. 4(1), 41-65.

Muyzer, G., DeWaal, E. C., Uitterlinden, A. G. (1993). Profiling of complex microbial populations by denaturing gradient gel electrophoresis analysis of polymerase chain reaction-amplified genes coding for 16S rRNA. Applied and environmental microbiology, 59:695-700.

Navarro, C. A., von Bernath, D., Jerez, C. A. (2013). Heavy metal resistance strategies of acidophilic bacteria and their acquisition: importance for biomining and bioremediation. Biological research, 46, 363-371. http://dx.doi.org/10.4067/S0716-97602013000400008

Oren, A. (2010). Acidophiles. Encyclopedia of life sciences. Macmillian Press, London. pp. 192-206. https://doi.org/10.1002/9780470015902.a0000336.pub2

Oulas, A., Pavloudi, C., Polymenakou, P., Pavlopoulos, G. A., Papanikolaou, N., Kotoulas, G., Arvanitidis C., Iliopoulos, L. (2015). Metagenomics: tools and insights for analyzing next-generation sequencing data derived from biodiversity studies. Bioinformatics and biology insights, 9, 76-88 https://doi.org/10.4137/BBI.S12462

White, G. F., Edwards, M. J., Gomez-Perez, L., Richardson, D. J., Butt, J. N., Clarke, T. A. (2016). Chapter Three - Mechanisms of Bacterial Extracellular Electron Exchange. In: Poole RK (ed) Advances in Microbial Physiology, vol 68. Academic Press, pp. 87-138. https://doi.org/10.1016/bs.ampbs.2016.02.002 